\title{
SOLVE ET REPETE Y SU INCIDENCIA EN EL DERECHO DEL OBLIGADO TRIBUTARIO A LA TUTELA JUDICIAL EFECTIVA
}

María del Rosario Medina ${ }^{1}$

\section{Introducción}

La locución latina solve et repete es utilizado por la doctrina nacional para referirse a la exigencia que impone la legislación fiscal, del pago del tributo como requisito previo para cuestionar en la órbita jurisdiccional o administrativa la legitimidad de la determinación de oficio de la obligación tributaria.

$\mathrm{Su}$ finalidad consiste en que para poder discutir en sede jurisdiccional acerca de la legitimidad de la pretensión fiscal, es necesario el previo pago de los montos que en concepto de tributos y sus accesorios la administración tributaria ordena hacer efectivos. ${ }^{2}$

En sentido amplio, la doctrina coincide en afirmar que el instituto significa que la impugnación de cualquier acto administrativo que implique un crédito a favor del Estado solamente es posible si el particular se aviene previamente a realizar el pago que se discute. ${ }^{3}$

$\mathrm{Su}$ origen se remonta al derecho romano, cuando en el periodo de la República el edicto del pretor invirtió el orden normal del procedimiento dando al contribuyente la condición de parte actora para obtener la declaración de ilegitimidad de la respectiva deuda reclamada por el fisco, de allí paso al derecho imperial, concretándose posteriormente en la ley italiana sobre lo contencioso administrativo de 1865 y en las normas tributarias de otras naciones.

En nuestro país nació como una creación pretoriana a través de la jurisprudencia de Corte Suprema de Justicia de la Nación, incorporándose luego en la legislación tributaria y legislación procesal en lo contencioso administrativo. La Ley Nacional $\mathrm{N}^{\circ} 11683$ de procedimientos Tributario adoptaba con rigor el

${ }^{1}$ Especialista en Tributación. Profesora titular de Derecho Financiero y Tributario Cátedra A de la Facultad de Derecho Ciencias Sociales y Políticas de la UNNE. Investigadora categorizada de la UNNE. 1978.

${ }^{2}$ Spila García Rubén. Principios de Derecho Procesal Tributario. Buenos Aires. Depalma,

${ }^{3}$ Garrido Falla Fernando, Tratado de Derecho Administrativo. Madrid. Instituto de Estudios Políticos 1958. 
instituto en varias disposiciones, hasta que la reforma introducida por la Ley $\mathrm{N}^{\circ}$ 15265-creadora del Tribunal Fiscal-atempero su rigidez, sin embargo, subsiste para las causas de menor cuantía que no se abren a la competencia del Tribunal Fiscal. Por otra parte, la mayoría de las provincias han regulado el instituto en los códigos tributarios provinciales y en las leyes en lo contencioso administrativo. Algunas han sido muy rigurosas exigiendo el pago previo del tributo como condición necesaria no sólo para el acceso a la instancia judicial, sino también para la deducción de los recursos administrativos. El Código Fiscal de la Provincia de Corrientes, se enrola en esta posición.

Con la reforma constitucional de 1994 la Convención Americana sobre Derechos Humanos (Pacto de San José de Costa Rica) adquirió rango constitucional (artículo 75 inc. 22) y con ello también el artículo 8 cuyo apartado 1 contiene una disposición relativa a la necesaria intervención de un juez o tribunal competente, independiente e imparcial, que asegure a los contribuyentes la discusión de cuestiones fiscales ante dichos organismos a los fines de obtener un pronunciamiento en respuesta a sus agravios contra los actos de la Administración, garantizándoles una efectiva tutela de sus derechos.

Frente a este derecho fundamental del contribuyente, el solve et repete se presenta como una amenaza a la garantía de la necesaria intervención de un juez imparcial para resolver asuntos fiscales .Ello ha generado múltiples debates en la doctrina y una extensa jurisprudencia.

Por tal razón el objetivo general del presente trabajo es explicar la situación actual del solve et repete en el derecho tributario argentino, a partir del análisis de su naturaleza jurídica y fundamentos teóricos, la evolución en la doctrina y jurisprudencia de la Corte Suprema de Justicia de la Nación para luego confrontarlo con el derecho fundamental de acceso a la jurisdicción y garantía de la tutela judicial efectiva.

\section{Fundamentos: Teorías que han tratado de justificar el instituto}

Desde la teoría se han esbozado diversas explicaciones sobre los fundamentos y naturaleza de la institución, unas de carácter político y otras jurídicas de carácter sustancial y de orden meramente procesal.

La teoria del privilegio a favor del Fisco: considera al solve et repete como un privilegio del fisco, establecido con una exclusiva finalidad práctica o política de que la actividad del Estado no resulte perturbada por dilaciones en 
la oportuna percepción de los tributos. ${ }^{4}$ Tiene una esencia que busca garantizar a ultranza el ingreso financiero en las arcas estatales, con independencia de las situaciones jurídicas sustanciales de los contribuyentes

La teoria de la ejecutividad y ejecutoriedad del adeudo tributario: sostiene que el instituto deriva de la presunción de legitimidad y ejecutoriedad del acto administrativo, más específicamente de la facultad ejecutoria del acto administrativo que determina el tributo, ya que no se encuentran en un plano de igualdad el contribuyente y el fisco, que posee facultades exorbitantes, debido precisamente a la necesidad de percibir el tributo de forma rápida para sustentar el aparato estatal y satisfacer las necesidades públicas.

Dentro de esta corriente se encuentran autores como Rafael Bielsa ${ }^{5}$ y Dino Jarach, ${ }^{6}$ quienes sostienen que en el derecho tributario están permanentemente presentes los principios de ejecutividad y ejecutoriedad del derecho administrativo.

La teoría de la autonomía del instituto: con una visión estrictamente tributarista, Achille Donato Giannini sostiene que el instituto no guarda relación con el principio de ejecutoriedad del acto administrativo, sino que se trata de una norma peculiar del derecho tributario. Afirma que:

El contenido de esta norma y las consecuencias prácticas que de ella derivan, son cosa distinta del principio de ejecutoriedad de la pretensión tributaria, siendo una norma peculiar del derecho tributario, con la finalidad de resultar un medio para impedir que el particular pida en juicio la tutela de su derecho sin el pago previo del tributo, ejerciendo sobre él una presión para obligarlo a cumplir, en tiempo oportuno, la obligación resultante de la liquidación.?

Benvenuto Griziotti ${ }^{8}$ lo considera como una institución autónoma del derecho financiero y reviste el carácter de medida protectora de política financiera,

${ }^{5}$ Bielsa, Rafael en Estudios de Derecho Público. T. II. Derecho Fiscal. Buenos Aires. Argentina. Depalma 1951, sostiene que el fundamento político económico es la necesidad de disponer de los recursos, ella resulta de la ejecutoriedad y no de la presunción de legitimidad del acto y que en cuanto al funcionamiento procesal del instituto, lo concibe como una cuestión prejudicial por cuanto el pago del impuesto debe ser previo a toda acción judicial.

${ }^{6}$ Jarach, Dino hace derivar el solve et repete de un principio general del derecho administrativo (ejecutoriedad) y cuyo carácter especial obedece a la naturaleza específica de los actos en que se exterioriza. Constituye un medio peculiar de tutela del crédito tributario del Estado. Curso Superior de Derecho Tributario, Buenas Aires Argentina, Cima 1967

${ }^{7}$ Gianini. Achille Donato “Solve et Repete", en Revista de Derecho Publico 1936, p. 349 y ss.

${ }^{8}$ Griziotti. Benvenuto. Principios de la Ciencia de las Finanzas Publicas, traducción de Dino Jarach, Buenos Aires, Argentina, Depalma, 1959. 
cuya finalidad, función o motivo es proteger las finanzas públicas, erigiendo una valla para los contribuyentes de mala fe, desalentando la promoción de acciones infundadas que puedan impedir el regular ingreso de los tributos en las arcas estatales.

Como se podrá advertir, la falta de uniformidad de fundamentos vertidos por la doctrina como así también aquellos que se lo niegan parece obedecer a la imposibilidad de atribuir una clara fundamentación jurídica al instituto ya que su finalidad es esencialmente política, consistente en impedir que mediante la controversia se obstaculice la recaudación, constriñendo en consecuencia al contribuyente al pago.

Posiciones doctrinarias que cuestionan el instituto: otro grupo de destacados autores, en posición que compartimos, consideran que se trata de un injusto privilegio fiscal, ${ }^{9}$ tanto para interponer los recursos administrativos como la acción judicial. Ello así, porque contraría principios jurídicos fundamentales en el estado de derecho, en tanto el particular afectado por el acto ilegal no puede obtener un pronunciamiento jurisdiccional si no paga previamente la pretensión de su acreedor.

En el mismo sentido José Osvaldo Casas, ${ }^{10}$ sostiene que el solve et repete constituye un privilegio injustificado a favor del fisco en franco abandono en el derecho comparado, por cuanto se encuentra en pugna con principios, garantías y derechos de rango constitucional.

\section{Doctrina de la Corte Suprema de Justicia de la Nación: Evolución}

El instituto ha sido ha sido ampliamente debatido en la jurisprudencia de nuestro máximo Tribunal, lo cual nos obliga a reseñar las líneas interpretativas acerca de los fundamentos que lo justifican.

Así, en un primer periodo de exigencia absoluta del pago previo del tributo a los efectos de evitar que el recurso extraordinario interpuesto por el apelante-el contribuyente- no obstaculice la normal percepción de la renta pública. Aparece de tal manera la fundamentación política del instituto.

9 Valdés Costa Ramón. Instituciones de Derecho Tributario. Buenos Aires, Argentina. Depalma, 2004.

${ }^{10}$ Casas José Osvaldo en "Tutela Jurisdiccional en materia Tributaria", Ponencia en las "III Jornadas Tributarias del MERCOSUR" 1levadas de cabo en la ciudad de Buenos Aires los días 26 al 28 de agosto 1999. 
Resulta interesante destacar que esta línea jurisprudencial no analizo per se la viabilidad constitucional del solve et repete, sino que hizo hincapié en la posibilidad de revisión por parte de la Corte federal, de las determinaciones de tributos por parte de los fiscos provinciales y como ello podía impactar en la oportuna y normal percepción de sus rentas.

Pero luego la Corte, ha efectuado un test de constitucionalidad del solve et repete, dando nacimiento de tal forma a los denominados por ella misma como supuestos de excepción a la rigurosa regla del pago previo.

Este segunda etapa jurisprudencial podemos ubicar a partir de los casos "Livorno SRL c/ Dirección de Vinos" (Fallos 247:181) Y "Destilerías Bodegas y Viñedos El Globo Ltda. S.A." (Fallos 261:101).

Estos trascendentes fallos efectúan un test de constitucionalidad del solve et repete, inclinándose por la validez, como principio general de la regla.

Ahora bien esta validez no reviste carácter absoluto. Ello obedece a que debe ceder en aquellos casos en que exista una desproporcionada magnitud del pago previo en relación con la concreta capacidad económica del recurrente, la cual podría tornar ilusorios sus derechos constitucionales e implicar un desapoderamiento de sus bienes.

De igual manera la Corte ha exigido en esta serie de fallos, la falta comprobada e inculpable de recursos económicos en manos del apelante, a los efectos de poder hacer frente al pago previo del tributo cuestionado. En esta línea jurisprudencial, el máximo tribunal también expuso que la regla del pago previo no encuentra sustento si ella involucra un verdadero desapropio o revela de manera inmediata e inequívoca propósitos persecutorios o desviación de poder de los fiscos involucrados en el litigio (Fallos 285:302).

La tercera etapa corresponde al periodo de ratificación del Pacto de San José de Costa Rica.: La cuestión adquirió mayor relevancia en la Corte, luego que nuestro país ratificara - en el año 1984- Ley $\left.N^{\circ} 23054\right)$ la Convención Americana de Derechos Humanos-Pacto de San José de Costa Rica-y el tribunal cimero le otorgo plena operatividad (in re: Ekmekdjan, Miguel c/Sofovich, Fallo 315:14895) donde asigno supremacía y operatividad al Tratado en el marco del ordenamiento jurídico argentino).

Hasta entonces la Corte convalidaba la constitucionalidad del solve et repte luego de efectuar un cotejo de dicha regla con lo normado por el artículo 18 de la Constitución Nacional. Sin embargo, y aquí deviene la importancia del instrumento internacional, desde 1984, la cuestión también debía evaluarse a la luz del articulo 8 inc. 1 del mencionado cuerpo normativo. 
Es recién en 1989 cuando la Corte resuelve los autos Micrómnibus Barrancas de Belgrano S.A., sentenciando la constitucionalidad del solve et repete, toda vez que el Pacto en nada hizo variar su posición sobre dicho recaudo, al considerar que el recurrente ni siquiera había alegado que le fuera imposible el cumplimiento del pago previo debido al excesivo monto del depósito, de tal forma de impedir real y efectivamente el ejercicio de su derecho de defensa. Por lo tanto la exigencia del pago previo seguía siendo compatible con el art. 18 de la Constitución Nacional y el artículo 8.1 de la Convención Americana de Derechos Humanos.

Como puede observarse, en esta etapa de la jurisprudencia-actualmente vigente-constituye un recaudo fundamental a la hora de impugnar la validez constitucional de la regla solve et repete, el hecho de alegar y acreditar que el pago del tributo discutido impide el ejercicio de derechos constitucionalmente consagrados. Sólo así puede atenuarse el rigorismo del instituto.

La cuarta etapa refiere al periodo de la reforma constitucional de 1994. En los casos" Expreso Sudoeste S.A. c/Provincia de Buenos Aires" (Fallos 319:3415) de fecha 27/12/96. "Cadesu Cooperativa de Trabajo Ltda. c/DGI" (Fallos 321:174, de fecha 11/6/98). En "Centro de Diagnostico de Virus SRL c/ AFIP.DGI" (Fallos 328:2938 de fecha 2/8/2005). La Corte reitero lo resuelto en Barrancas de Belgrano S.A. manifestando las únicas excepciones a la validez constitucional del solve et repete son aquellas que contemplan fundadamente situaciones patrimoniales concretas de los particulares a fin de evitar que el pago previo se traduzca, a causa de falta comprobada e inculpable de medios pertinentes para enfrentar la erogación, en un real menoscabo del derecho a la igualdad en el primer o de los precedentes, o en la defensa en juicio, en el segundo de las causas, o de ambos en el tercer fallo.

Particular relevancia adquiere en este periodo jurisprudencial, el control que deben efectuar las autoridades públicas, de cualquier poder constituido, de su accionar a la luz de lo dispuesto por el Pacto de San José Costa Rica, a razón del llamado "control de convencionalidad" el cual debe ser efectuado de oficio, lo cual es admitido expresamente por la Corte.

La omisión de tal importante función institucional acarrea severas consecuencias para los Estados que han ratificado el instrumento internacional: a saber: su responsabilidad internacional.

En tal sentido la Corte expresó: La Corte Interamericana ha señalado que es consciente de que los jueces y tribunales internos están sujetos al imperio 
de la ley y por ello están obligados a aplicar las disposiciones vigentes en el ordenamiento jurídico. Pero cuando un Estado ha ratificado un tratado internacional como la Convención Americana de Derechos Humanos, sus jueces, como parte del aparato del Estado, también están sometidos a ella, lo que los obliga a velar por los efectos de las disposiciones de la Convención no sean mermados por la aplicación de leyes contrarias a su objeto y fin y que desde un inicio carecen de efectos jurídicos (Fallos 330:3248). Recientemente el máximo tribunal ha recetado la jurisprudencia de la Corte Interamericana y manifestado la posibilidad de efectuar de oficio, a través de los jueces, el mencionado control de convencionalidad.

En la quinta y última etapa la jurisprudencia se advierte un giro copernicano en la exigencia del recaudo del pago o previo. Interesan aquí los casos "Gibelco SRL c/ AFIP" (Fallos G 2212 XXXIX, RHE de fecha 5/6/2007) y Origines AFJP c/ AFIP (Fallos 331:2480 de fecha 4/11/2008). En el primero, a propósito de la presentación de una garantía real por parte de la recurrente a los efectos de sortear el solve et repete la Corte decidió que dentro de la ratio legis de las normas que exigen en materia fiscal el pago previo para la procedencia formal de los recursos intentados, uno de los principales es evitar que quien en definitiva resulte deudor pueda eludir su compromiso insolentándose en el ínterin de la discusión. Por ende, la solución brindada por la Cámara rechazando de plano la posibilidad de garantizar el cumplimiento de la hipotética sentencia favorable, luce contraria a una de las razones legales que impusieron la exigencia mencionada.

Esta sentencia encuentra su trascendencia en el hecho de posibilitar el afianzamiento del pago del tributo discutido y de escapar de esta manera de la rigurosa regla del pago previo. Es por ello que la Corte afirma categóricamente que una de las principales razones que motorizan el instituto solve et repete es "evitar que quien en definitiva resulte deudor pueda eludir su compromiso insolentándose en el ínterin de la discusión".

En definitiva, la doctrina de la Corte Suprema de Justicia de la Nación a través de sus diversas integraciones considera al solve et repete como plenamente vigente y sólo para reducir los efectos de su aplicación ha elaborado los llamado por el ella misma como supuestos de excepción a la rigurosa regla del pago previo.

La actual doctrina del Máximo Tribunal se sustenta sobre la posibilidad de garantizar el pago del tributo para evitar la aplicación del solve et repete. 


\section{La Tutela Judicial efectiva}

El derecho fundamental de todo contribuyente de acceder a tribunales independientes en defensa de sus derechos ha sido consagrado en especial en la Convención Americana sobre Derechos Humanos, ${ }^{11}$ suscrita en San José de Costa Rica en noviembre de 1969 , pacto que con la reforma constitucional de 1994 adquirió jerarquía constitucional.

Del artículo 8.1 del pacto citado, surge con claridad que el contribuyente para la determinación de sus obligaciones fiscales, tiene los siguientes derechos: a) a ser oído con las debidas garantías; b) a que el proceso se desarrolle dentro de un plazo razonable; y c) a ser juzgado por un juez o tribunal competente; independiente; e imparcial, establecido con anterioridad por la ley.

El derecho fundamental a la tutela judicial efectiva que la clausula convencional consagra apunta a eliminar las trabas que impidan u obstaculizan el acceso a la jurisdicción 3, como también a asegurar el ejercicio pleno de la jurisdicción y a evitar que queden ámbitos de la actividad de la administración tributaria inmunes al control judicial.

Conlleva explícitamente la interdicción de la indefensión. Ello implica, el libre $^{12}$ acceso a los órganos jurisdiccionales sin obstáculos injustificables y que no excluya el conocimiento de las pretensiones opuestas por los contribuyentes justiciables..$^{13}$

${ }^{11} \mathrm{El}$ art. 8.1 del Pacto de San José de Costa Rica textualmente determina: "Toda persona tiene derecho a ser oída, con las debidas garantías y dentro de un plazo razonable por un juez o tribunal competente, independiente e imparcial, establecido con anterioridad por la ley, en la sustanciación de cualquier acusación penal formulada contra ella o para la determinación de sus derechos y obligaciones de orden civil, laboral, fiscal o de cualquier otro carácter"'.

12 En este sentido ha expresado la Comisión Interamericana de Derechos Humanos que "el principio de la tutela judicial efectiva puede traducirse en la garantía de la libre entrada a los tribunales para la defensa de los derechos e intereses frente al poder público, aún cuando la legalidad ordinaria no haya reconocido un recurso o acción concreto. Este principio implica lógicamente un conjunto de garantías elementales en la tramitación de los procesos judiciales". Informe 105/99 emitido en el caso 10.194, "Palacios, Narciso -Argentina", emitido el 29/9/99, publicado en LL, 2000-F, p. 59.

${ }^{13} \mathrm{Al}$ respecto cabe señalar que la Comisión Interamericana de Derechos Humanos, a través del informe 105/99 emitido en el caso 10.194, "Palacios, Narciso -Argentina", (publicado en LL, 2000-F, p.594,) ha expresado: "Las garantías a la tutela judicial efectiva y al debido proceso imponen una interpretación más justa y beneficiosa en el análisis de los requisitos de admisión a la justicia, al punto que por el principio "pro actione", hay que extremar las posibilidades de interpretación en el sentido más favorable al acceso a la jurisdicción". 
Se trata de un derecho que presenta un contenido constitucional amplio que comprende el derecho: a) a ocurrir ante los tribunales de justicia y a obtener de ellos una sentencia útil, b) a acceder a una instancia judicial ordinaria y a lograr un control judicial suficiente sobre lo actuado en sede administrativa, c) a un juez natural e imparcial, d) a la eliminación de las trabas que impidan u obstaculizan el acceso a la jurisdicción, e) a la interpretación de las normas reguladoras de los requisitos de acceso a la jurisdicción en forma favorable a la admisión de la pretensión evitándose incurrir en hermenéuticas ritualistas (in dubio pro actione), f) al desarrollo del proceso en una dimensión temporal razonable.

Desde esa perspectiva queda clara que la clausula convencional garantiza al contribuyente el derecho al libre acceso a la jurisdicción contenciosa tributaria sin condicionamientos ni obstáculos, por lo tanto, en nuestra opinión la exigencia del pago previo del tributo como requisito para el cuestionamiento de la determinación de la obligación impositiva no resulta compatible con dicha garantía de tutela judicial efectiva.

En tal sentido la doctrina nacional se ha pronunciado en forma cada vez más coincidente en contra del mantenimiento del solve et repete e, incluso, ha sostenido que tal instituto ha sido implícitamente expulsado del ordenamiento jurídico como consecuencia de la adhesión y ratificación por la Argentina de la Convención Americana de Derechos Humanos o Pacto de San José de Costa Rica.

José Osvaldo Casas (2004), al referirse a las garantías que resguardan a los valores del Estado de derecho, sostiene que

"resulta inimaginable que frente a dos partes en pugna, una jurídicamente fuerte y poderosa —el Estado- y otra a menudo débil y desvalida en garantías - el contribuyente-, pueda negarse el acceso a la jurisdicción con la excusa de la falta de pago previo del tributo."

Por su parte, Héctor B. Villegas (1994) al comentar la cláusula 8.1 del Pacto de San José de Costa Rica señala que:

Cuando el Tratado señala que las personas tienen derecho a ser oídas por un juez o tribunal competente, independiente e imparcial, para la determinación de sus derechos y obligaciones de carácter fiscal, está indicando que ese derecho garantizado a la defensa debe ser concedido sin condiciones ni obstáculos de ninguna especie. 


\section{Conclusión}

En base a lo expuesto es imposible negar que existe siempre una tensión entre el solve et repete y derechos de mayor jerarquía, como los de la tutela judicial efectiva y acceso a la jurisdicción. Tensión que a nuestro criterio, en el actual Estado Constitucional de Derecho debiera resolverse por el legislador, derogando la norma de menor entidad.

Resulta necesario establecer un procedimiento tributario que garantice al contribuyente los derechos y garantías que conforman el bloque constitucional actual y en este lineamiento, consideramos que los códigos fiscales provinciales deben garantizar en forma efectiva el derecho de acceso a la jurisdicción, el derecho de defensa, el del debido proceso, no siendo suficiente para ello las propuestas que formulan algunas modificaciones legislativa provinciales de atenuación del instituto mediante la admisión garantías, avales o seguros de caución.

\section{Bibliografía}

Casas, José Osvaldo. La revisión judicial de la acción administrativa en materia tributaria. Buenos Aires,, Argentina, Hammurabi. 2004.

Giuliani Fonrouge, Carlos. Derecho Financiero. Buenos Aires. Argentina. Depalma 2008.

Valdez Costa Ramón. Instituciones de Derecho Tributario. Depalma. Buenos Aires. Argentina. 2004.

Villegas, Héctor B. Curso de Finanzas, Derecho Financiero y Tributario. Buenos Aires, Argentina. Depalma. 1994.

Spisso, Rodolfo R."Acciones y Recursos en Materia Tributaria", Abeledo Perrot. Buenos Aires, Argentina. 2010. 